\title{
Medical Robotics in Cardiac Surgery
}

\author{
Stephan Jacobs and Volkmar Falk \\ Department of Cardiac Surgery, Heartcenter, University of Leipzig
}

Germany

\section{Introduction}

Surgical telemanipulators are obviously used in cardiac surgery to provide the surgeon in a confined space the same stereoscopic vision, full dexterity, unimpaired hand-eye-alignment and tactile feedback, as in open surgery. This is the basic concept that enables the controlled fine soft tissue manipulation that is needed in bypass grafting, valve surgery, ASD Closure and Cardiac Tissue Ablation for Atrial Fibrillation.

When computer-enhanced telemanipulation systems were introduced into the field of cardiac surgery some 8 years ago there was obviously a lot of enthusiasm and expectations were high. As with any new technology early adopters strived for scientific recognition and the use of robotics in the cardiac surgical suite received a great deal of media attention. With more experimental and clinical experience, the potential benefits but also the limitations of the currently available technology became visible [1,2]. Initially two systems were available but the Computer Motion Zeus system soon proved to be of limited clinical use due to the fact that the system offered only limited dexterity making endoscopic reconstructive microsurgery (such as performing a coronary anastomosis) difficult. Intuitive's da Vinci system is therefore the only Surgical Telemanipulator that is currently being used. A total of 2984 endoscopic cardiac procedures world wide (reported in a company based registry) have been performed in 2005 and increase steadily. This includes Totally Endoscopic Coronary Artery Bypass Grafting (TECAB) procedures or small access single- or multivessel coronary artery bypass procedures with endoscopic uni- or bilateral ITA harvest (1784 procedures).

\section{Development of Robotic Cardiac Surgery}

Computer enhanced Telemanipulation systems have enabled total endoscopic coronary artery bypass grafting both on the arrested and more recently also on the beating heart, a procedure that was unthinkable only few years ago. Every new technique in the medical sector runs through an evolutionary process. Thoracoscopic ITA-take down was followed by a Minimally Invasive Direct Coronary Artery Bypass Grafting (MIDCAB) procedure. After an initial learning curve that was demonstrated in all centers using the telemanipulator, the totally endoscopic coronary bypass grafting procedure on pump was achieved. The conversion rate to MIDCAB was in the range of $30 \%$. At the same time computer assisted mitral valve repair (MVR) was established. Successful MVR has been performed with all critical steps of the repair procedure being performed intracorporeally 
[3]. Because of the necessity of a small right thoracotomy, the advantages of this procedures compared to a conventional minimal invasive access are small. The number of MVR increased within 450 cases in 2004 over 600 in 2005 to approximately 950 in 2006 (reported in a company based registry).

After the development of endoscopic stabilizers which allow free articulation of the pads and thus provide easier placement, coronary artery bypass grafting on the beating heart was feasible. The conversion rate (elective conversion to a MIDCAB procedure) with this approach was high $(>50 \%)$ in the beginning and LAD occlusion times exceed those reported for MIDCAB procedures [4]. Among the difficulties determination of optimal anastomotic site, excessive target vessel calcification and incomplete vessel occlusion limitations have been overcome with a new generation of stabilizer and with a sufficient irrigation system for back-bleeding from septal branches. The conversion rate in overall patients was about $30 \%$ but decreased over the time to nearly $10 \%$. The efficacy of TECAB tested by angiography was similar to conventional bypass procedures. Confirming data of a European multicenter registry including 220 TECAB procedures will be published soon. From these data, it can be concluded that the use of the daVinci telemanipulation systems is safe, provided the user has a low threshold for conversion.

\section{System Setup and Operative Details of TECAB Procedure}

The patient is placed in a supine position with a small positioning roll placed caudal of the left scapula to lift the thorax and drop the left shoulder. The patient is draped in a way to allow for standard sternotomy and saphenous vein harvesting or a left lateral minithoracotomy if required. The lower axillary line needs to be accessible for port placement. A holding arm for the endostabilizer is mounted to the OR table rail on the patient's right side and the operating table is rotated $10^{\circ}$ to $15^{\circ}$ to raise the patient's left side. The camera port is placed in the 5 th intercostals space $2 \mathrm{~cm}$ medial of anterior axillary line. A $30^{\circ}$ scope angled up is inserted and the thoracic cavity is scanned for anatomical landmarks and to exclude the presence of adhesions. The surgical cart is then brought to the table and the camera attached to the central arm (Figure 1). Under direct vision, the right instrument port is placed in the third intercostal space medial to anterior axillary line and thus in the center of a triangle which is created by the manubrium, acromion and the camera port. Insertion of the trocar is monitored by endoscopic vision.

The left instrument port is placed in the seventh intercostal space medial to the anterior axillary line (Figure 2). The instrument arms are centred for optimal range of motion, by adjusting the respective set-up joints, and the instruments are inserted. The instruments are moved along the entire length of ITA to evaluate for external collisions between patient's body and instrument arms; instrument arms and camera arm. The ideal position for the setup joints of the instrument arms is $90^{\circ}$ between the primary and secondary axis ("shoulder") and $45^{\circ}$ between the secondary and tertiary axis ("elbow"). For the camera arm the net-sum of angles should be $0^{\circ}$ resulting in straight alignment of the scope and the central column. With this setup there should be only little if no necessity to move the setup joints during the procedure. The remote centers should be placed correctly within the ports to provide the highest precision and lowest friction.

In order to maximize space in a closed chest environment single lung ventilation of the right lung is required. $\mathrm{CO}_{2}$-insufflation is necessary to increase the available space between the sternum and the heart and enhance exposure. After single right-lung ventilation is initiated 
$\mathrm{CO}_{2}$-insufflation is begun for adequate visualization. Insufflation pressures in the range of 10$12 \mathrm{mmHg}$ are usually well tolerated, despite an increase in right ventricular filling pressures, a decrease of intrathoracic blood volume index and right ventricular ejection fraction. Cardiac output and blood pressure may decrease despite a compensatory increase in heart rate.

After the set-up of the system the surgical procedure starts with dissection of the left internal thoracic artery (LITA). The anatomic structures (anatomic landmarks) such as the phrenic nerve and the subclavian artery are easily identified. LITA take down starts by retracting and incising the facia immediately covering the LITA with low power monopolar cautery. The LITA is always in view during blunt dissection moving from the lateral to medial edge keeping a pedicle including the lateral veins without the facia. Dissection is performed from the first intercostal space down to the level of the bifurcation. Side branches are cut using low energy cautery.

The pedicle is not detached from the chest wall until the anastomosis is finally performed to avoid torsion of the graft and any interference during pericardiotomy. The mediastinal and diaphragmatic attachments of the pericardium are bluntly dissected to allow the pericardial sac to drop and to facilitate insertion of the endostabilizer later during the procedure. The epicardial fat is removed beginning medially. Care must be taken to avoid injury of the phrenic nerve. The pericardiotomy is performed with a longitudinal incision in pericardium over the suspected course of the left anterior descending artery (LAD). The pericardiotomy should not be extended to far lateral and over the apex as the heart may drop out of the pericardial sac. Identification of the LAD is facilitated by identifying anatomical landmarks such as the apex of the heart, the grove between the medial aspect of the left atrial appendage and pulmonary artery and the ventricular septum that can be identified by differences in the contractile pattern of the right and left ventricles. The ideal site for the anastomosis is then determined by absence of visible atheromatous plaques and avoiding proximity to bifurcations. The range of motion for the left and right instrumente is verified in the anastomotic region to ensure freedom from collisions or singularities and to allow for set up changes at this point if required. It maybe necessary to flip the endoscope from $30^{\circ}$, angled up to $30^{\circ}$, angled down to enhance visualization. At this time the ideal length of the graft can be assessed. The distal end is then prepared for the anastomosis. This is done leaving the concomitant veins intact to provide counter traction during LITA preparation and to keep the orientation of the graft. The distal end of the LITA is skeletonized. It is advantageous to free the distal end (up to $2 \mathrm{~cm}$ ) of all adventitial tissue to facilitate suturing. After heparinization (an Activated Clotting Time (ACT) of 300 seconds is recommended) a vascular clamp is placed approximately $2 \mathrm{~cm}$ proximal to the transection site of the LITA. The clamp maybe attached to the chest wall in order to provide additional counter traction and to facilitate exposure of the graft during the initial stitches for the anastomosis. The LITA is clipped distally and cut and spatulated in preparation for the anastomosis. Markers on the scissors allow for assessment of the correct length of the cut. Graft patency is confirmed by briefly releasing the vascular clamp. In case of insufficient flow, the procedure should be converted to open. Further endoscopic manipulation of a graft with insufficient flow is strongly discouraged. A $12 \mathrm{~mm}$ subxyphoid cannula is inserted under endoscopic vision. Before introduction of the Endostabilizer, temporary silastic occlusion tapes and a 7cm 7-0 double-armed Prolene suture are inserted and stored in the mediastinum. The Endostabilizer is then introduced under endoscopic vision by the patient side surgeon and positioned above the LAD target site. Vacuum lines and irrigating saline line are connected 
and the Multilink Irrigator is advanced into the field of view. The console surgeon then positions the stabilizer feet parallel to the LAD target site. After suction is applied, the feet are locked into position externally. After blunt dissection of the anastomotic target site, the silastic tapes are placed proximal and distal to the anastomotic site. It is helpful to cut the epicardium with the blunt knife before the dull needle is placed through the underlying muscle. Care must be taken to leave enough space $(2 \mathrm{~cm})$ between the two occlusion tapes. The LAD is occluded by lowering the self-locking plate onto the vessel and anchoring the silastic tape. Using a $15^{\circ}$ sharp blade the arteriotomy is performed and enlarged with Potts Scissors. The initial incision should be very limited to allow control of residual bleeding from septal branches or incomplete vascular occlusion. Spots of visible atheroma should be avoided. Transection of the LITA is completed at this time and the graft is brought in close proximity of the target site. If graft length is critical a stay suture to the epicardium may prevent excess tension at the anastomotic site. The anastomosis is best performed by beginning at the middle of the medial wall distant to the surgeon suturing inside-out on the LITA and outside-in on the LAD towards and around the heel. This way, there is less resistance for needle penetration through the less fixed graft tissue. The anastomosis is completed using the second needle going inside-out on the LAD and outside-in on the LITA around the toe. During suturing it is important to tense the suture after each stitch in order to avoid anastomotic leakage. After the needles are broken off, an instrument knot is tied. Since there is only limited tactile feedback, visual control is of utmost importance. The occlusion tapes and the vascular clamp are released and evacuated through an instrument port. After pleural effusion is drained under vision, the stabilizer and instruments are withdrawn and the left lung is ventilated.

\section{Results}

TECAB was performed initially on the arrested heart using the Port-Access technique with femoro-femoral bypass, endoaortic balloon clamping and applying cardioplegic arrest. CPB time and cross-clamp time were in the range of 80-120 and 40-60 minutes respectively. The reported patency rate for the TECAB procedure on the arrested heart ranged from 95 to $100 \%$ prior to discharge and $96 \%$ at 3 months follow-up angiography and thus equalled the patency rates of conventional bypass surgery. However, operating times were in the range from 4 to 6 hours for a single bypass graft. In a more recent analysis angiographic patency rate in selected patients was $98,2 \%(61 / 62)$ and the conversion rate was $23 \%(27 / 111)$, mostly related to problems with the Port-Access system or peripheral cannulation [5].

Endoscopic coronary artery bypass grafting on the beating heart is technically more challenging [6,7]. In a recent multicenter registry the data of five centers were accumulated. Based on an intention-to-treat, the conversion rate (elective conversion to a MIDCAB procedure) was $33 \%$ (37/117). Conversions were mostly due to the inability to locate or dissect the LAD, the presence of heavy target vessel calcification and rarely other conditions such as arrhythmia or hemodynamic instability [5]. Take-down of the LITA is now a routine procedure that can be performed in 30 to 40 minutes. Time is lost for setting up the stabilizer and preparing the anastomotic area. LAD occlusion times are usually in the range of 25-40 minutes and thus exceed those reported for MIDCAB procedures. Total operating times for a beating heart TECAB procedure range from 2.5 to 3.5 hours. The patency rates for completed beating heart TECAB procedures are in the range of 92 to $94 \%$ [5]. 
The use of a telemanipulation system is currently restricted to few indications (single vessel bypass grafting of the LAD, occasionally double vessel grafting) but it is conceivable that it may be used for endoscopic multi-vessel procedures in the near future [8]. A number of steps that occur between ITA take-down and performing the anastomosis are still challenging due to the lack of assistance, limited space, the lack of fine tactile feedback and a limited number of instruments. Among the difficulties are the handling of excessive epicardial fat, determination of the optimal site for an anastomosis, target vessel calcification, and back-bleeding from septal branches. In addition, difficulties with positioning of the stabilizer or incomplete immobilization, render beating heart closed chest bypass grafting difficult. A low threshold for conversion is mandatory to avoid any risk to the patient. Elective conversion is safe and should not be considered a failure.

\section{Current potential Solutions}

It is the ultimate wish of the patient for less invasive therapy that has driven the development for endoscopic cardiac surgery.

There is room for improvement and the fact that technical developments usually occur in incremental steps and may take time to become clinically available, limits acceptance. Over the years a number of iterations both in soft- and hardware components have been implemented in the system based on critique and input from surgeons around the world. With the second generation of the telemanipulation system, the daVinci S, some difficulties, that arise from design constraints inherent to the architecture, are solved with the development of a stabilization device, placed on the $4^{\text {th }}$ robotic cart arm. The application of multi-modal 3D imaging, surface registration and computational modeling of the range of motion of the robotic arms in an individual patient data-set optimizes preoperative planning of the procedure and allow for intraoperative navigation [9].

Beside good results, one reasons for conversion to MIDCAB was inability to perform the anastomosis due to lack of orientation. Identifying coronary pathology and to define the ideal location for an anastomosis in the absence of tactile feedback was observed and procedures failed. To solve these problems a distal endoscopic Coupling Device, a simple yet effective and time saving technique for anastomotic coupling was introduced to facilitate beating heart TECAB. The endoscopic "Ventrica system" was evaluated at the Heartcenter Leipzig in the animal lab and clinically used by the Frankfurt group [10].

\section{Perspectives}

The use of intraoperative imaging is growing due to the need of updated information in order to perform finer, more challenging interventions. Current uses of intraoperative imaging require the surgeon to interpret the images and decide what the next action should be. It has been shown to be advantageous to assist the surgeon by performing semiautomatic image-guided instrument control in certain interventional steps and allow the surgeon to concentrate on more important aspects. The surgeon is released from some simple and repetitive tasks which in turn increases his situational awareness and produces an improvement of the human factors, as well as of the patient safety. Therefore integrations of "automated or semi-automated components" for soft tissue manipulation might be the solution. Involving automation in a highly variable, deformable moving environment is still 
technically challenging and automation will clearly not be the answer in cardiac surgery. But shared anatomy, dividing the control of the robotic

system into the user and the system itself, provides the benefit of each component. These are the cognitive abilities of the human and the high precision and less inertia of the machine. Based on intraoperative imaging and feedback control, a soft tissue manipulation is semiautomatically possible and may prove beneficial in selected applications.

\section{Conclusion}

The DaVinci Telemanipulation system has been introduced to provide the human operator with dexterity in confined space. After successfully beginning with IMA-takedown and achieving some TECAB cases on pump, the technique was underestimated by surgeons. The lack of rapid improvement and the time consuming procedure led to frustration and many centers did not proceed. Minimally invasive cardiac surgery is challenging and it takes a lot of experience to get used to the system to complete a TECAB procedure. With a step by step program and the sensibility to overcome some limitations, forcing developments of new technology, the computer enhanced surgery can be successfully performed. With refinements in telemanipulator technology and the development of adjunct devices to enhance exposure the technique of computer enhanced endoscopic cardiac surgery will further evolve and may prove beneficial for selected patients.

\section{Figures}

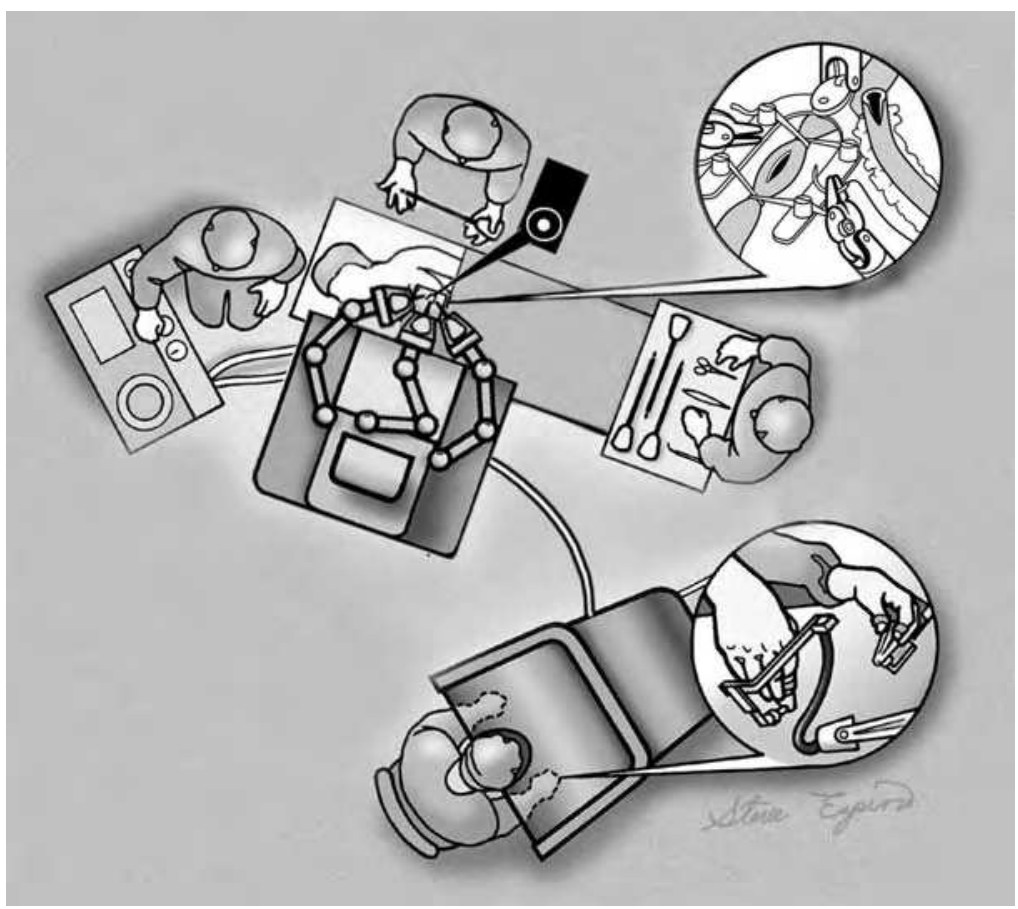

Figure 1. Schematic illustration of operating room setup 


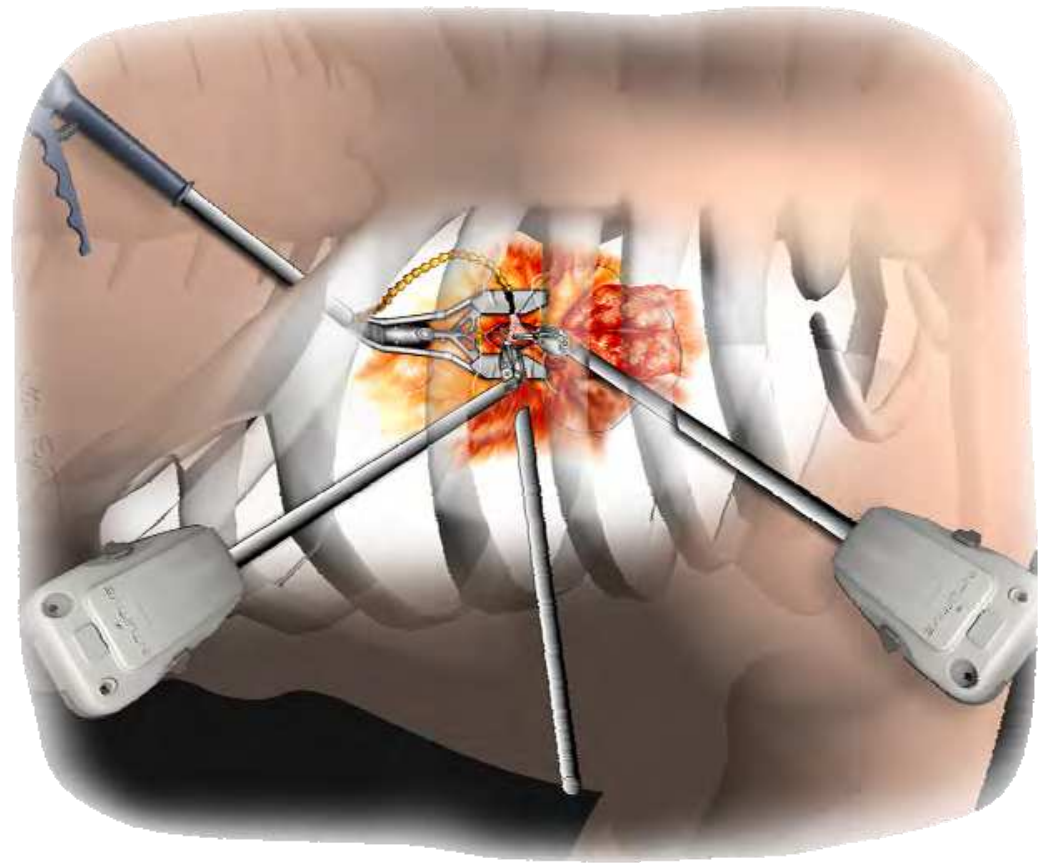

Figure 2. Schematic semitransparent illustration of port set-up in relation to the target site

\section{References}

Falk V, Diegeler A, Walther T, Bannusch J, Bucerius J, Raumans J, Autschbach R, Mohr FW: Total endoscopic coronary artery bypass grafting. Eur J Cardiothorac Surg 2000;17:38-45 [1]

Falk V, Fann JI, Grünenfelder J, Daunt D, Burdon TA,: Total endoscopic computer enhanced beating heart coronary artery bypass grafting. Ann Thorac Surg 2000;70:2029-2033 [2]

Rodríguez E, Kypson AP, Moten SC, Nifong LW, Chitwood WR. Robotic mitral surgery at East Carolina University: a 6 year experience Int J Med Robot. 2006 Sep;2(3):211-5 [3]

Jacobs S, Falk V, Holzhey D, Mohr FW: Perspectives in endoscopic cardiac surgery. Comput Biol Med. 2006 Dec 19 [4]

De Cannière D, Wimmer-Greinecker G, Cichon R, Gulielmos V, Van Praet F, SeshadriKreaden U, Falk V. Feasibility, Safety and Efficacy of Closed Chest CABG:Early European Experience. .J Thorac Cardiovasc Surg submitted [5]

Kappert U, Cichon R, Schneider J, Gulielmos V, Tugtekin SM, Matschke K, Schramm I, Schüler S: Closed chest coronary artery bypass surgery on the beating heart with the use of a robotic system. J Thorac Cardiovasc Surg 2000;120:809-811[6]

Falk V, Diegeler A, Walther T, Jacobs S, Raumans J, Mohr FW: Total endoscopic off-pump coronary artery bypass grafting. Heart Surgical Forum 2000;3:29-31 [7] 
Stein H, Cichon R, Wimmer-Greinecker G, Ikeda M, Hutchinson D, Falk V: Totally endoscopic coronary artery bypass surgery using the da vinci surgical system: a feasibility study on cadaveric models. Heart Surg Forum 2003;6:E183-190 [8]

Falk V, Mourgues F, Adhami L, Jacobs S, Thiele H, Nitzsche S, Mohr FW, Coste-Manière E. Cardio Navigation - Planning, Simulation and Augmented Reality in Robotic assisted endoscopic bypass grafting. Ann Thorac Surg 2005;79:2040-7 [9]

Falk V, Walther T, Stein H, Jacobs S, Walther C, Rastan A, Wimmer-Greinecker G, Mohr FW: Facilitated Endoscopic Beating Heart Coronary Bypass Grafting using a Magnetic Coupling Device. J Thorac Cardiovasc Surg 2003 Nov;126(5):1575-9 [10] 


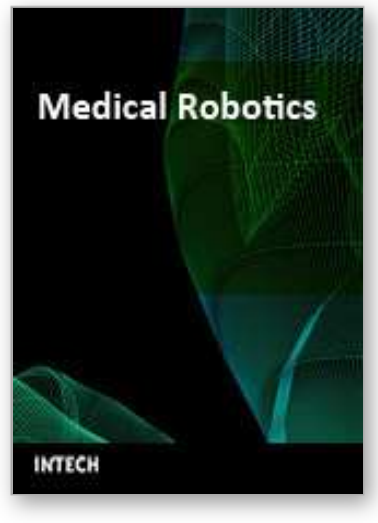

\author{
Medical Robotics \\ Edited by Vanja Bozovic
}

ISBN 978-3-902613-18-9

Hard cover, 526 pages

Publisher I-Tech Education and Publishing

Published online 01, January, 2008

Published in print edition January, 2008

The first generation of surgical robots are already being installed in a number of operating rooms around the world. Robotics is being introduced to medicine because it allows for unprecedented control and precision of surgical instruments in minimally invasive procedures. So far, robots have been used to position an endoscope, perform gallbladder surgery and correct gastroesophogeal reflux and heartburn. The ultimate goal of the robotic surgery field is to design a robot that can be used to perform closed-chest, beating-heart surgery. The use of robotics in surgery will expand over the next decades without any doubt. Minimally Invasive Surgery (MIS) is a revolutionary approach in surgery. In MIS, the operation is performed with instruments and viewing equipment inserted into the body through small incisions created by the surgeon, in contrast to open surgery with large incisions. This minimizes surgical trauma and damage to healthy tissue, resulting in shorter patient recovery time. The aim of this book is to provide an overview of the state-of-art, to present new ideas, original results and practical experiences in this expanding area. Nevertheless, many chapters in the book concern advanced research on this growing area. The book provides critical analysis of clinical trials, assessment of the benefits and risks of the application of these technologies. This book is certainly a small sample of the research activity on Medical Robotics going on around the globe as you read it, but it surely covers a good deal of what has been done in the field recently, and as such it works as a valuable source for researchers interested in the involved subjects, whether they are currently "medical roboticists" or not.

\title{
How to reference
}

In order to correctly reference this scholarly work, feel free to copy and paste the following:

Stephan Jacobs and Volkmar Falk (2008). Medical Robotics in Cardiac Surgery, Medical Robotics, Vanja Bozovic (Ed.), ISBN: 978-3-902613-18-9, InTech, Available from:

http://www.intechopen.com/books/medical_robotics/medical_robotics_in_cardiac_surgery

\section{INTECH}

open science | open minds

\section{InTech Europe}

University Campus STeP Ri

Slavka Krautzeka 83/A

51000 Rijeka, Croatia

Phone: +385 (51) 770447

\section{InTech China}

Unit 405, Office Block, Hotel Equatorial Shanghai

No.65, Yan An Road (West), Shanghai, 200040, China

中国上海市延安西路65号上海国际贵都大饭店办公楼 405 单元

Phone: +86-21-62489820 
Fax: +385 (51) 686166

Fax: +86-21-62489821

www.intechopen.com 
(C) 2008 The Author(s). Licensee IntechOpen. This chapter is distributed under the terms of the Creative Commons Attribution-NonCommercialShareAlike-3.0 License, which permits use, distribution and reproduction for non-commercial purposes, provided the original is properly cited and derivative works building on this content are distributed under the same license. 